\title{
Maskulinitas yang Berubah: Analisis Wacana Konten Youtube Tysna Saputra
}

\author{
Sherly Angeline, Farid Rusdi \\ Sherlyoffice108@gmail.com, farid@fikom.untar.ac.id \\ Fakultas Ilmu Komunikasi Universitas Tarumanagara
}

\begin{abstract}
Masculinity has the understanding that a man should have a strict, male and rude attitude. A man who has a gentle nature, does not like heavy sports and others will be considered a taboo in society. Masculinity that has changed in society along with the development of the times, this is indicated by the emergence of male beauty vloggers who discuss about beauty, self-care, style of dress and so on. One of them is Tysna Saputra. Through his YouTube channel, Tysna Saputra uploaded a video titled SKIN CARE GUYS at CHILDREN COST! Tysna practices self care steps for men. This, builds men's awareness to be more able to take care of themselves and not feel taboo when doing it. The method used by the author is a qualitative research method, namely by using Van Djik's critical discourse analysis techniques. The method used is online data observation and tracking. The results of observations made by the author are that through Tysna Saputra's video proves that a man can do beauty freely and shows that the concept of masculinity has changed in society. A man can perform self-care and beauty without reducing the existing masculinity. This is related to Van Djik's theory of analysis.
\end{abstract}

Keywords: beauty vlogger, masculinity, youtube, discourse analysis.

\begin{abstract}
Abstrak
Maskulinitas memiliki pengertian bahwa seorang laki-laki sudah seharusnya memiliki sikap yang tegas, jantan dan kasar. Seorang laki-laki yang memiliki sifat lemah lembut, tidak menyukai olahraga berat dan lainnya akan dianggap sebagai hal yang tabu di masyarakat. Maskulinitas yang telah berubah di masyarakat seiring dengan berkembangnya zaman, hal ini ditunjukkan dengan bermunculannya para beauty vlogger laki-laki yang membahas mengenai kecantikan, perawatan diri, gaya berpakaian dan sebagainya. Salah satunya adalah Tysna Saputra. Melalui kanal YouTubenya, Tysna Saputra mengunggah video dengan judul SKIN CARE COWOK harga ANAK KOST!. Tysna mempraktikkan langkah - langkah merawat diri untuk laki-laki. Hal ini, membangun awareness kaum laki-laki untuk bisa lebih merawat diri dan tidak merasa tabu saat melakukannya. Metode yang digunakan oleh penulis adalah metode penelitian kualitatif, yaitu dengan memakai teknik analisis wacana kritis Van Djik. Metode yang digunakan adalah observasi dan penelusuran data online. Hasil dari observasi yang dilakukan penulis adalah bahwa melalui video Tysna Saputra membuktikan bahwa seorang laki-laki bisa melakukan kecantikan dengan bebas dan menunjukkan bahwa konsep maskulinitas telah berubah di dalam masyarakat. Seorang lelaki dapat melakukan perawatan diri dan kecantikkan tanpa mengurangi maskulinitas yang ada. Hal ini dikaitkan dengan teori analisis Van Djik.
\end{abstract}

Kata Kunci: beauty vlogger, maskulinitas, youtube, analisis wacana. 


\section{Pendahuluan}

Maskulinitas merupakan kejantanan seorang laki-laki yang dihubungkan dengan kualitas seksualnya sehingga masyarakat memiliki asumsi bahwa maskulinitas memiliki kriteria dan ciri-ciri yang tertentu. Barker, Nasir (2007:1) mengungkapkan bahwa maskulinitas tradisional secara umum dapat menganggap tinggi nilai-nilai yang sudah ada, yaitu antara lain kekuatan, kekuasaan, ketabahan, aksi, kendali, kemandirian, kepuasan diri kesetiakawanan laki-laki, dan kerja.

Selama bertahun - tahun, label maskulinitas seorang laki-laki sudah ditentukan oleh masyarakat dengan bertolak ukur dengan standar yang telah mereka buat. Laki-laki haruslah bersikap jantan, tegas, tegap dan lainnya. Bahkan dalam beberapa kasus, jika seseorang laki-laki melakukan kekerasan seperti berkelahi, memukul pasangannya akan dianggap umum dan alamiah karena memang seperti itulah seorang laki-laki harusnya. Hal ini sungguh sangat disayangkan karena kekerasan dalam bentuk apapun, seharusnya tidak pernah dibenarkan.

Secara garis besar, maskulinitas dapat digambarkan sebagai suatu label yang telah diberikan terhadap laki-laki dan bertentangan dengan label feminimitas yang diberikan kepada perempuan. Hal ini merupakan dua sifat yang sangat bertolak belakang dan berlawanan. Jika setiap insan tidak memenuhi karakter yang telah di labelkan, maka akan dianggap sebagai suatu kesalahan dan menyimpang.

Seseorang telah dibentuk sedari kecil untuk mengikuti label masyarakat yang telah ditetapkan oleh keluarga dan lingkungan terdekatnya. Hal ini bertujuan untuk menghindari terbentuknya sikap yang menyimpang dan mendapat tempat di masyarakat. Baker, Nasir (2007:3) menjelaskan bahwa laki-laki adalah manusia yang memiliki kebebasan dan pantas untuk melakukan apapun tanpa terbebani oleh normanorma kepantasan dan kesopanan. Laki-laki tidak harus selalu mempunyai sifat agresif, kuat secara fisik, individualistis dan sikap jantan lainnya.

Perkembangan zaman yang semakin maju, citra maskulinitas laki-laki secara perlahan mengalami perubahan dalam masyarakat. Hal ini dibuktikan dengan munculnya berbagai jenis produk kecantikan dan perawatan yang ditujukan untuk laki-laki, gaya pakaian yang semakin modern dan hal lainnya.

Di era 1980 maskulinitas dipandang sebagai new man. Beynon (Nasir, 2007:3) mengkategorikan new man menjadi dua yaitu new man as narcissist dan new man as nurturer. Maskulinitas pada era ini berkembang dengan cara yang sangat unik dan berbeda.

New man as narcissist adalah generasi penerus dari zaman hippies (era 60-an) yang memiliki ketertarikan dalam cara berpakaian dan selera musik pop. Dalam kategori ini, laki-laki dijadikan sebagai objek seksual bisnis dan munculnya berbagai produk komersil yang luar biasa. Gaya hidup seorang lelaki narcissist adalah yuppies flamboyan dan parlente. Gaya berpakaian yang nyentrik, mobil, kemewahan merupakan artefak personal yang dominan dalam gaya hidup ini.

Sedangkan new man as nurturer adalah permulaan awal dari reaksi seorang lelaki terhadap feminisme. Seorang lelaki dapat memiliki sifat alamiah kelembutan sebagai seorang ayah dalam mengurus anaknya dan sebagai seorang kepala rumah tangga. Dalam kategori ini, laki-laki dapat mendukung perempuan untuk memiliki keterlibatan dalam peran seorang laki-laki di masyarakat.

Maskulinitas dalam era 1990-an memiliki konsep yang mengarah kepada sifat seorang lelaki yang memiliki kekerasan, macho dan kacau. Hal ini dipicu oleh musik 
band dan bidang olahraga kasar seperti football, rugby, soccer yang sangat popular pada saat itu di kalangan pria. Melalui label konsumerisme,lelaki menyatakan bahwa dirinya harus menjadi lebih macho,menyukai olahraga berat, pemabuk dan memiliki hubungan intim dengan para perempuan (Beynon, dalam Nasir, 2007: 4).

Memasuki era 2000-an, sifat maskulinitas seorang laki-laki yang telah diterapkan sebelumnya berubah dengan adanya suatu yang khas dan memiliki terminologi baru. Dalam terminology ini, muncullah istilah laki-laki metroseksual. Lelaki metroseksual adalah seseorang yang memiliki sifat yang lembut, pandai merawat diri, mementingkan penampilan serta memiliki gaya hidup yang teratur, royal, hedonis dan perfeksionis.

Mark Simpson (1994) mengemukakan bahwa metroseksual adalah seseorang yang berkemampuan dan memiliki uang untuk dihabiskan dan biasanya bertempat di kota metropolis. Seorang pria metroseksual menjadikan dirinya sendiri sebagai preferensi seksualnya. Ia tidak akan ragu untuk mengeluarkan biaya yang banyak dalam perawatan dirinya agar terlihat seperti yang diinginkan. Menjalani perawatan di seluruh tubuh bahkan menghilangkan bulu-bulu yang ada di lengan atau kaki bahkan punggung dilakukan untuk mendapatkan gambaran dirinya yang ia dambakan. Hal ini bertolak-belakang dengan konsep maskulinitas laki-laki yang haruslah memiliki bulu di lengan atau kakinya agar dianggap jantan.

Setelah melewati selama hampir tiga dekade dan memasuki era yang baru, seakan ingin mendobrak dan mengubah standarisasi yang telah ditetapkan oleh masyarakat dan budaya selama ini, para beauty influencer laki-laki bermunculan dan membuktikan bahwa laki-laki yang melakukan perawatan diri bukanlah sebuah hal yang menyimpang.

Influencer merupakan seseorang yang memiliki suara, pengaruh, kekuasaan untuk mengungkapkan pendapatnya dan memiliki kuasa dalam memengaruhi keputusan pembelian orang lain. Sedangkan beauty memiliki arti kecantikan. Sehingga dapat disimpulkan bahwa Beauty Influencer adalah seseorang yang memiliki kekuatan dan pengaruh dalam bidang kecantikan baik secara verbal maupun non-verbal.

Melalui latar belakang yang telah dijabarkan, maka dari itu peneliti ingin membahas mengenai representasi maskulinitas yang dilakukan oleh seorang beauty influencer laki-laki. Salah satunya adalah, Tysna Saputra. Melalui video-videonya, ia menjadi inspirasi baik dalam segi merawat diri, gaya berpakaian. Peneliti akan meneliti salah satu videonya yang diberi dengan judul SKIN CARE COWOK harga ANAK KOST!.

\section{Metode Penelitian}

Dalam penelitian ini, peneliti akan menggunakan metode pendekatan penelitian kualitatif. Penelitian kualitatif merupakan penelitian yang berlandaskan dengan filsafat postpositivisme dan digunakan dalam meneliti kondisi obyek yang alamiah. Analisis data dapat berupa induktif atau kualitatif dan hasil penelitian akan lebih menekankan kepada generalisasi.

Peneliti akan menggunakan metode penelitian analisis wacana. Tujuan utama dari analisis wacana ini adalah untuk menyingkapkan keburaman wacana yang memiliki kontribusi pada penghasilan hubungan yang tidak seimbang terhadap para peserta wacana. Wacana tidak dipandang dan dipahami sebagai hanya objek dalam studi bahasa, tetapi dapat digunakan sebagai alat dan tujuan praktik tertentu. 
Halliday dan Hasan (1976) berpendapat bahwa wacana merupakan suatu kesatuan semantik dan bukan kesatuan gramatikal. Hal ini juga didukung dengan teori Van Djik (1977) yang menyatakan bahwa wacana adalah bangunan teoretis yang abstrak dan belum dapat dilihat sebagai perwujudan fisik bahasa (teks).

Untuk melakukan metode analisis wacana ini, peneliti akan menggunakan juga teknik observasi dan pengumpulan data secara online. Observasi adalah proses pengamatan sistematis dari aktivitas manusia dan pengaturan fisik dalam kegiatan yang berlangsung secara monoton yang bersifat secara alami untuk menghasilkan sebuah fakta.

Metode penelusuran online yang akan dilakukan oleh peneliti adalah dengan meneliti salah satu dari video narasumber melalui kanal YouTube miliknya. Bungin (2007) mengungkapkan bahwa penelusuran data online melalui internet atau media jaringan lain yang menyediakan fasilitas berbasis online.

Teknik analisis data yang akan digunakan oleh peneliti adalah teknik analisis wacana. Eriyanto (2011) mengungkapkan bahwa wacana merupakan salah satu kata yang banyak disebut, meskipun begitu hal ini dapat membuat rancu dan menyebabkan kebingungan. Dalam analisis wacana kritis, bahasa dapat dilihat sebagai faktor penting. Bahasa yang digunakan dapat dilihat sebagai ketimpangan kekuasaan dalam masyarakat yang sedang, atau sudah terjadi.

Analisis wacana kritis memiliki lima karakteristik yang telah dinyatakan oleh Teun A. van Dijk, yaitu:

a. Tindakan: sebuah bentuk dari interaksi dan hanya berlaku secara internal semata. Hal ini dilakukan melalui komunikasi verbal dan non verbal serta memiliki kesadaran penuh dan dapat dipertanggung jawabkan.

b. Konteks: Hal lain yang memengaruhi pemakaian bahasa seperti partisipan wacana, latar, jenis kelamin, umur, etnis, waktu dan sebagainya.

c. Historis: wacana yang diproduksi akan dapat dimengerti karena memiliki konteks sebelumnya.

d. Kekuasaan: Wacana yang muncul dalam teks, percakapan membawa sebuah pesan yang sangat kuat dan merupakan bentuk dari pertarungan kekuasaan.

e. Ideologi: Kajian sentral dalam analisis wacana kritis. penggunaan pesan baik secara individu / kelompok memiliki persuasi sehingga hal itu tampak absah dan benar.

Teknik keabsahan data yang akan digunakan oleh penulis adalah menggunakan pendekatan triangulasi data. Triangulasi data adalah upaya untuk memanfaatkan pengamat lainnya guna melakukan pengecekan kembali derajat kepercayaan. Sugiyono (2009) menyatakan triangulasi sumber data adalah menggali kebenaran informasi tertentu melalui berbagai metode dan sumber perolehan data.

\section{Hasil Temuan dan Diskusi}

Dalam penelitian ini, peneliti akan meneliti salah satu video narasumber yang berjudul SKIN CARE COWOK harga ANAK KOST! Video ini telah ditayangkan sebanyak 2,800,386 kali dan mendapatkan sekitar 57.000.000 likes. Peneliti akan mengaitkan setiap adegan dalam video narasumber dengan lima karakteristik yang telah dijabarkan oleh Van Djik sebelumnya.

Gambar 1. Video Narasumber 


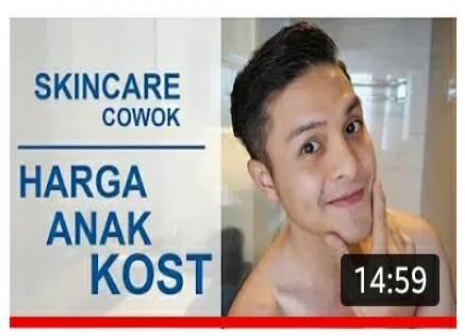

Sumber: youtube.com/tysnasaputra
SKIN CARE COWOK harga ANAK : KOST!

Tysna Saputra

1 year ago $\cdot 2.7 \mathrm{M}$ views

Berdasarkan dengan karakter di atas, peneliti menemukan bahwa dalam setiap adegan yang dilakukan oleh narasumber dalam videonya, terdapat unsur-unsur karakteristik analisis wacana. Berikut adalah analisis wacana yang telah ditemukan oleh peneliti:

- Narasumber melakukan interaksi kepada para pengikutnya melalui kolom komentar dan terus berbicara sambil melibatkan para penonton. Narasumber juga memiliki peran sebagai pemberi informasi dan memengaruhi audience untuk membeli berbagai produk yang telah ia sarankan. Unsur yang terdapat dalam adegan ini adalah unsur tindakan yang dilakukan secara sadar oleh narasumber dan memiliki tanggung jawab penuh.

- Konteks yang terdapat dalam video ini terlihat sangat matang. Narasumber mempertimbangkan dan membuat latar yang bagus agar video ini menjadi lebih menarik untuk dilihat. Hal ini juga memengaruhi penyampaian pesan dan penggunaan bahasa.

- Unsur historis yang terdapat dalam video ini sudah diungkapkan oleh narasumber pada awal pembukaan video. Sebelum ini, narasumber telah mengunggah video serupa dan melakukan video update atas permintaan dari subscriber. Produk-produk yang digunakan dalam video ini memiliki harga yang terjangkau dan dapat dipercaya kualitasnya.

- Unsur kekuasaan yang digunakan oleh narasumber sebagai seorang beauty vlogger adalah dalam menggiring opini subscriber agar membeli produk yang ditawarkan. Kekuasaan yang muncul dalam bentuk tulisan, peristiwa, percakapan dan tindakan memiliki unsur kekuasaan untuk mengendalikan suatu peristiwa atau wacana. Melalui videonya, narasumber memiliki kuasa ini baik secara langsung maupun tidak langsung.

- Ideologi merupakan wacana yang dominan dalam mempersuasi dan memiliki pesan tersembunyi dalam penggunaan bahasa yang digunakan sehingga tampak absah dan benar. Narasumber merekomendasikan suatu produk kepada penontonnya berdasarkan pengalaman pribadi yang telah ia alami. Hal ini merupakan cerminan dasar dari setiap video yang diunggah oleh narasumber.

Gambar 2. Mengaplikasikan produk 


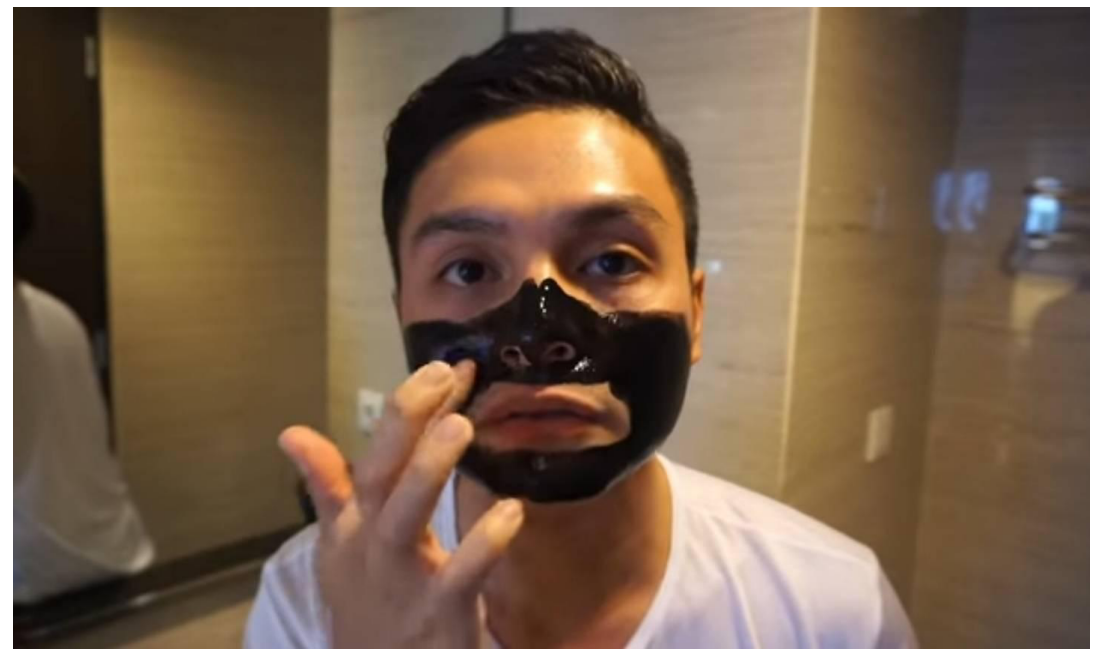

Sumber: youtube.com/tysnasaputra

\section{Kesimpulan}

Melalui analisis wacana berdasarkan video YouTube Tysna Saputra, peneliti menemukan bahwa sekarang ini sudah banyak produk perawatan yang beredar yang ditujukan untuk laki-laki. Hal ini membuktikan bahwa label maskulinitas yang berada di masyarakat sudah secara perlahan berubah. Selain itu, saat ini sudah banyak bermunculan YouTuber laki-laki yang membahas mengenai perawatan dan kecantikan salah satunya adalah Tysna Saputra. Konsep maskulinitas yang harus selalu gagah, tegap dan jantan perlahan telah pudar. Saat ini, laki-laki dapat melakukan dan bebas dalam merawat diri entah itu dari skincare, gaya berpakaian, cara berperilaku dan sebagainya.

Sebagai seorang beauty influencer laki-laki, Tysna Saputra tidak malu dalam mengekspresikan dirinya. Hal ini dilakukan karena ia ingin menjadi inspirasi untuk banyak orang, bahwa berbeda itu bukan berarti suatu hal yang tabu / menyimpang.

Ternyata hal ini sangat memengaruhi bagaimana cara penyampaian pesan, pemilihan kata, latar, historis agar tidak terjadi kesalahpahaman sehingga pesan yang ingin disampaikan dapat tersampaikan dengan baik dan diterima oleh masyarakat sesuai dengan teori analisis wacana Van Djik.

\section{Ucapan Terima Kasih}

Pada kesempatan ini peneliti mengucapkan rasa syukur dan terima kasih kepada Tuhan Yang Maha Esa, kepada keluarga serta pembimbing yang telah membantu peneliti dalam menyelesaikan skripsi dan jurnal, yaitu Bapak Farid Rusdi. Serta kepada adik, sahabat, teman-teman seperjuangan lainnya dan narasumber penelitian yang telah membantu peneliti dalam proses penyelesaian penelitian ini. 
Sherly Angeline, Farid Rusdi: Maskulinitas yang Berubah: Analisis Wacana Konten Youtube Tysna Saputra

\section{Daftar Pustaka}

Eriyanto. (2011). Analisis Wacana Kritis : Pengantar Analisis Teks Media.

Kanal YouTube Tysna Saputra : https://www.youtube.com/tysnasaputra 